\title{
Carotenoid oxidation products: From villain to saviour?*
}

\author{
Michel Carail and Catherine Caris-Veyrat ${ }^{\ddagger}$ \\ INRA, UMR 408, site Agroparc, 84914 Avignon Cédex 9, France
}

\begin{abstract}
Carotenoid oxidation products have various structures, among which epoxides and apo- or seco-carotenoids are the two main families. Although both these compound types are widely found in the natural world, the sensitivity of carotenoids to oxidation means they can also be an unwanted presence in in vitro assays. On the other hand, carotenoid oxidation products have also provided chemists with useful chemical tools for the structural identification of carotenoids, and in the natural world they are important biological mediators for plants and animals. In vitro, carotenoid oxidation products have been found to exert various effects which are either potentially beneficial or, on the contrary, detrimental to human health. However, to date, few carotenoid oxidation products have been found in humans.

In order to isolate and characterize carotenoid oxidation products and identify their mechanism of formation, we set up two chemical oxidation systems. Lycopene was oxidized with potassium permanganate in a biphasic system to produce the fullest possible range of apo-lycopenals and some diapocarotene-dials. Biomimetic chemical systems of a heminic enzyme center were shown to oxidize lycopene and $\beta$-carotene into different families of molecules. Analysis by high-performance liquid chromatography coupled with a diode arrayUV/vis detector and a mass spectrometry detector (HPLC-DAD-MS) was used to gain insight into the possible mechanisms of formation of the carotenoid oxidation products formed by these biomimetic systems.
\end{abstract}

Keywords: carotenoids; seco-carotenoids; apo-carotenoids; lycopene; biomimetic; apo-lycopenals.

Carotenoid oxidation products are derived from naturally occurring carotenoids by a chemically or enzymatically driven oxidation reaction. The carotenoid polyene system is structured in such a way that epoxide functions are frequently formed on the polyene skeleton. The most stable and, thus, the most frequently observed of these functions are the monoepoxide in 5,6- and the diepoxide in 5,6;5',6' positions, or their rearrangement products, creating a furanoid cycle in 5,8 and/or 5', $8^{\prime}$ positions (Fig. 1). We chose to enlarge the definition of carotenoid oxidation products to compounds derived from a carotenoid by at least one oxidation step, but other reactions may also occur, such as a carbon-carbon bond cleavage, thus forming apo-carotenoids (Fig. 1). Any of the carbon-carbon double bonds of the carotenoid are susceptible to cleavage. When the fission occurs on a cyclic bond, the C-40 carbon skeleton is retained and the products are called seco-carotenoids (Fig. 1). This paper focuses on apo- and seco-carotenoids formed through a formal oxidative cleavage and which will be considered carotenoid oxidation products.

\footnotetext{
*Paper based on a presentation at the $14^{\text {th }}$ International Symposium on Carotenoids, Edinburgh, Scotland, 17-22 July 2005. Other presentations are published in this issue, pp. 1477-1557.

‡Corresponding author: E-mail: caris@avignon.inra.fr
} 

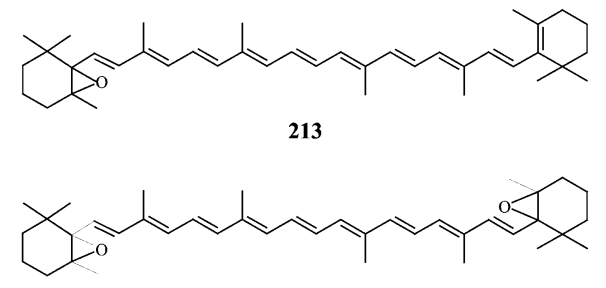

257

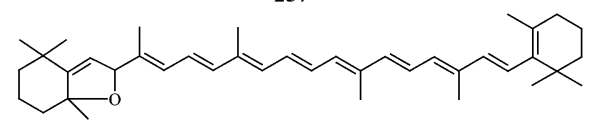

239
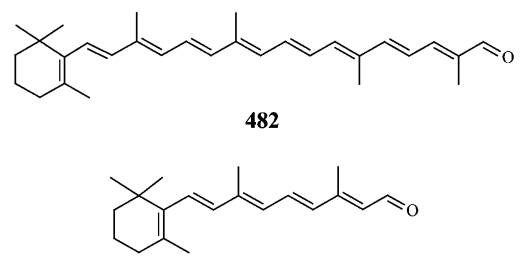

retinal

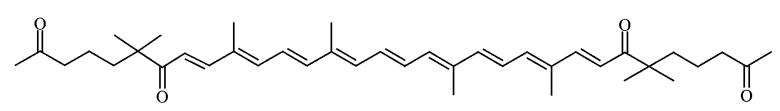

562

Fig. 1 Chemical structures of carotenoid epoxides: $\beta$-carotene-5,6-epoxide (213), $\beta$-carotene-5,6;5',6'- di-epoxide (257), and $\beta$-carotene-5,8-epoxide (239 = mutatochrome), apo-carotenals: $\beta$-apo-8'-carotenal (482) and retinal $(=\beta$-apo-15-carotenal $=$ vitamin $A$ aldehyde $)$, and a seco-carotenoid: $\beta$-carotenone $(\mathbf{5 6 2})$. The compound numbers correspond to those used in ref. [1].

There are 70 naturally occurring carotenoid epoxides [1], 43 of which have been fully characterized. These compounds can be formally considered as oxidation products as defined above, but they first have the status of carotenoids. They are indeed found in vivo and are possibly biosynthesized from the corresponding nonoxidized carotenoid. Some 117 naturally occurring apo-carotenoids, 88 of which have been fully identified, and another 6 naturally occurring seco-carotenoids have been referenced as carotenoids [1], thus representing around $15 \%$ of the carotenoids numbered so far. This subfamily of carotenoids would be even larger with the addition of compounds that are presently excluded by nomenclature rules [2,3] that dictate that they are not deemed to be carotenoids in the absence of two central methyl groups [at C20 and C20'], as in retinal (Fig. 2). However, carotenoid oxidation products are not always natural, and the sensitivity of carotenoids to oxidation means they can be formed during experiments with carotenoids, e.g., extraction from natural matrices. Thus, carotenoid oxidation products carry a "negative" image and are often associated with the carotenoid degradation process. However, these compounds, particularly apo-carotenoids, have a complex history and may be much more than simple villains.

Carotenoid oxidation products were first used as tools for the structural identification of carotenoids [4]. Carotenoids were oxidized expressly to form small fragments which could be analyzed with the techniques available at the time. The chemical structure of the parent carotenoids was deduced from those of its oxidation products. For instance, the number of side-chain methyl groups was first determined by oxidation using potassium permanganate in alkaline solution, thus forming acetic acid [5,6]. Step-wise degradation by oxidation with alkaline potassium permanganate or chromic acid as well as ozonolysis were used to obtain larger fragments that could be used to deduce the carotenoid structure [4]. The formula of lycopene was even confirmed in 1935 by obtaining long-chain degradation products through chromic acid oxidation [7]. More recently, oxidation by manganese dioxide was used as a chemical derivatization in microscale tests to elucidate the presence of allylic primary and secondary hydroxy groups in carotenoids, with the allylic aldehyde or ketone formed exhibiting a bathochromic-shifted UV/vis spectrum [8]. Carotenoid oxidation products can also act as markers of the antioxidant activity of carotenoids [9]. Carotenoid oxidation products can, therefore, be analyzed to gain insight into the antioxidant mechanism of carotenoids. In the natural world, carotenoid oxidation products are important mediators presenting different properties. Volatile carotenoid-derived compounds such as norisoprenoids are well known for their aroma properties [10]; examples include the cyclic norisoprenoid $\beta$-ionone (Fig. 2) or the noncyclic pseudoionone or neral potentially derived from lycopene [11] (Fig. 2). Carotenoid oxidation products are also important bioactive mediators for plant 
<smiles>CC(=O)/C=C/C1=C(C)CCCC1(C)C</smiles>

$\beta$-ionone<smiles>CC(C)=CCC/C(C)=C\C=O</smiles>

neral<smiles>CC(=O)/C=C/C=C(\C)CCC=C(C)C</smiles>

pseudo $($ or $\psi)$-ionone<smiles>CC1(C)CC(=O)C=C(O)[C@@]1(O)/C=C/C=C\C(=O)O</smiles>

abscisic acid

Fig. 2 Chemical structures of some of the carotenoid oxidation products of biological interest.

development [12-14], the best known example being abscisic acid (Fig. 2). Apo-carotenoids act as visual and volatile signals to attract pollination and seed dispersal agents in the same way as carotenoids do, but they are also plant defense factors and signalling molecules for the regulation of plant architecture.

With the exception of retinoids, it is only about 10 years ago that other carotenoid oxidation products were first thought to possibly exert biological effects in humans, being implicated in either the prevention [15,16] or promotion of degenerative diseases. X. D. Wang [17] has published an excellent review on this topic. The underlying mechanisms involved in the activities of carotenoid oxidation products are either due to a possible role as precursors of retinoids, which would be the active species for positive effects, or to their own, specific activities. This latter case is illustrated by the activity of non-provitamin A carotenoid oxidation products, such as those derived from lycopene. Different types of apparently beneficial activities have been demonstrated in vitro for carotenoid oxidation products, including induction of gap-junctional communications [18,19], growth inhibition of leukaemia [20] and cancer cells [21-23], induction of apoptosis in cultured cells [24-26], and gene activation [27,28]. However, to date, none of the compounds tested in the cited studies have been detected in vivo in humans, neither in human plasma or other biological fluids, nor in human tissues, but the oxidative metabolite of lycopene, 2,6-cyclolycopene-1,5-diol found in humans and tomato products [29-31] also showed in vitro upregulation of connexin43 gene expression [32] and in vitro growth inhibition of human prostate cancer cells [33]. Carotenoid oxidation products are also suspected to be involved in the adverse effects of high doses of $\beta$-carotene supplementation in smokers and asbestos workers (ATBC [34] and CARET [35] studies), as well as in smoke-exposed ferrets [36]. The mechanisms potentially involved have been investigated in vitro. $\beta$-apo-8'-carotenal, an eccentric cleavage oxidation product of $\beta$-carotene, was shown to be a strong inducer of CYP1A1 in rats, whereas $\beta$-carotene itself was not active [37]. Cytochrome P450 (CYP 450) enzymes thus induced could enhance the activation of carcinogens and the destruction of retinoic acid [38]. Another study showed that a mixture of oxidative metabolites of $\beta$-carotene, but not $\beta$-carotene, was able to increase the binding of benzo[a]pyrene to DNA [39]. Other mixtures of $\beta$-carotene cleavage products have been shown to induce oxidative stress in vitro [40], exert cytotoxic and genotoxic effects [41], and inhibit gap junction intercellular communications 
[42]. It has been suggested that these detrimental effects could possibly occur in vivo following the intake of high doses of carotenoids.

It should be underlined that even though the chemical structures of the compounds named "carotenoid oxidation products" leave little doubt as to the molecule from which they are derived, there is still very little known about the mechanisms by which they are formed, and the biochemical pathways involved have only very recently been identified. A significant number of carotenoid cleavage dioxygenases (CCDs) have been described in plants and microorganisms that can be classified into different families according to their substrate specificity or the position of the cleaved carbon-carbon double bond. The 9-cis-epoxycarotenoid dioxygenases (NCEDs) cleave the 11,12 carbon-carbon double bond of 9-(Z=cis)-carotenoids like 9-(Z)-violaxanthin, it was first found in maize [43] and is involved in the abscisic acid biosynthetic route. NCEDs have also been found in Arabidopsis thaliana [44]. Other CCDs cleave various carotenoids at different positions, e.g., the CCD from the cyanobacteria Microcystis $\mathrm{F}$ at the 7,8 and 7',8' positions [45], and the CCD found in Crocus sativus (CsZCD) in which it catalyzes the oxidative cleavage of zeaxanthin into crocetindial and $\beta$-cyclocitral [46]. A CCD found in the tropical plant Bixa orellana cleaves lycopene in 5,6 and 5',6' positions, thus producing precursors of the pigment bixin (annatto) [47]. Other CCDs cleaving various carotenoids symmetrically at the 9,10 and 9',10' positions have been identified in A. thaliana (AtCCD1) [48] and in grape berries from Vitis vinifera $\mathrm{L}$. [49]. In animals, the relationship between $\beta$-carotene and vitamin A (= retinol), which was suspected for almost 90 years [50], was proven to occur in vivo in 1930 [51]. The oxidative cleavage of $\beta$-carotene formally generates retinal, which is then reduced into retinol, but issues related to symmetrical vs. asymmetric cleavage and chemical vs. biochemical cleavage remained controversial for a long time. Although chemical cleavage has not yet been shown to occur in vivo, cleavages catalyzed by enzymes have been identified. An enzyme catalyzing the central cleavage of $\beta$-carotene was characterized 40 years ago [52,53] but could only recently be partially purified via cloning of its encoding cDNAs from different organisms [54-58]. This enzyme was shown to be a monooxygenase-type enzyme [59]. The only existing X-ray-based structural identification of a carotenoid cleavage enzyme was published very recently, and concerns a retinal-forming carotenoid oxygenase from the cyanobacteria Synechocystis sp. PPC 6803 [60]. Also very recently, a mammalian enzyme catalyzing the asymmetric oxidative cleavage of $\beta$-carotene and lycopene at the $9^{\prime}, 10^{\prime}$ carbon-carbon double bond, thus forming the corresponding $\beta$-apo-10'-carotenoids and $\beta(\psi)$-ionone, has been characterized [61]. Asymmetric cleavage of $\beta$-carotene was suspected to occur in vivo for almost 30 years since $\beta$-apo-8-, $-10^{\prime}-$, and -12 -carotenals were isolated from the intestines of chickens and rats [62]. Later, $\beta$-apo-carotenoids and retinoids were found in ferrets $[63,64]$, which is an animal model for the study of carotenoid metabolism in humans. The findings on the biosynthetic route to apo-carotenals in animals and the discovery of an enzyme catalyzing the asymmetric cleavage of carotenoids have generated heightened interest in carotenoid oxidation products and their possible biological role in vivo.

Chemists have also been able to obtain carotenoid oxidation compounds by either partial or total synthesis or by direct oxidation of carotenoid precursors. Thus, apo-8'-lycopenal was able to be synthesized in 1966 [65], followed by apo-6'-lycopenal a few years later [66]. More recently, the ozonide of cantaxanthin was obtained by chemical oxidation of cantaxanthin [67]. The ready availability of carotenoid oxidation products through chemical methods will facilitate their use as standard identification tools in complex media such as biological fluids, and enable in vitro investigation of their biological activity. Moreover, these studies can help in understanding the mechanisms by which they can be either chemically or biochemically cleaved in vivo. In this context, we have developed and applied two oxidation methods to lycopene and $\beta$-carotene.

The first chemical oxidation method was performed in biphasic medium using the hydrophilic oxidant potassium permanganate [68]. The phase-transfer agent cetyltrimethylammoniumbromide was used to achieve contact of the hydrophilic oxidant with the lipophilic carotenoid lycopene dissolved in methylene chloride/toluene $(50 / 50, \mathrm{v} / \mathrm{v})$. The reaction mixture was analyzed after $1 \mathrm{~h}$ at room temperature using high-performance liquid chromatography coupled with a diode array-UV/vis detector and a 

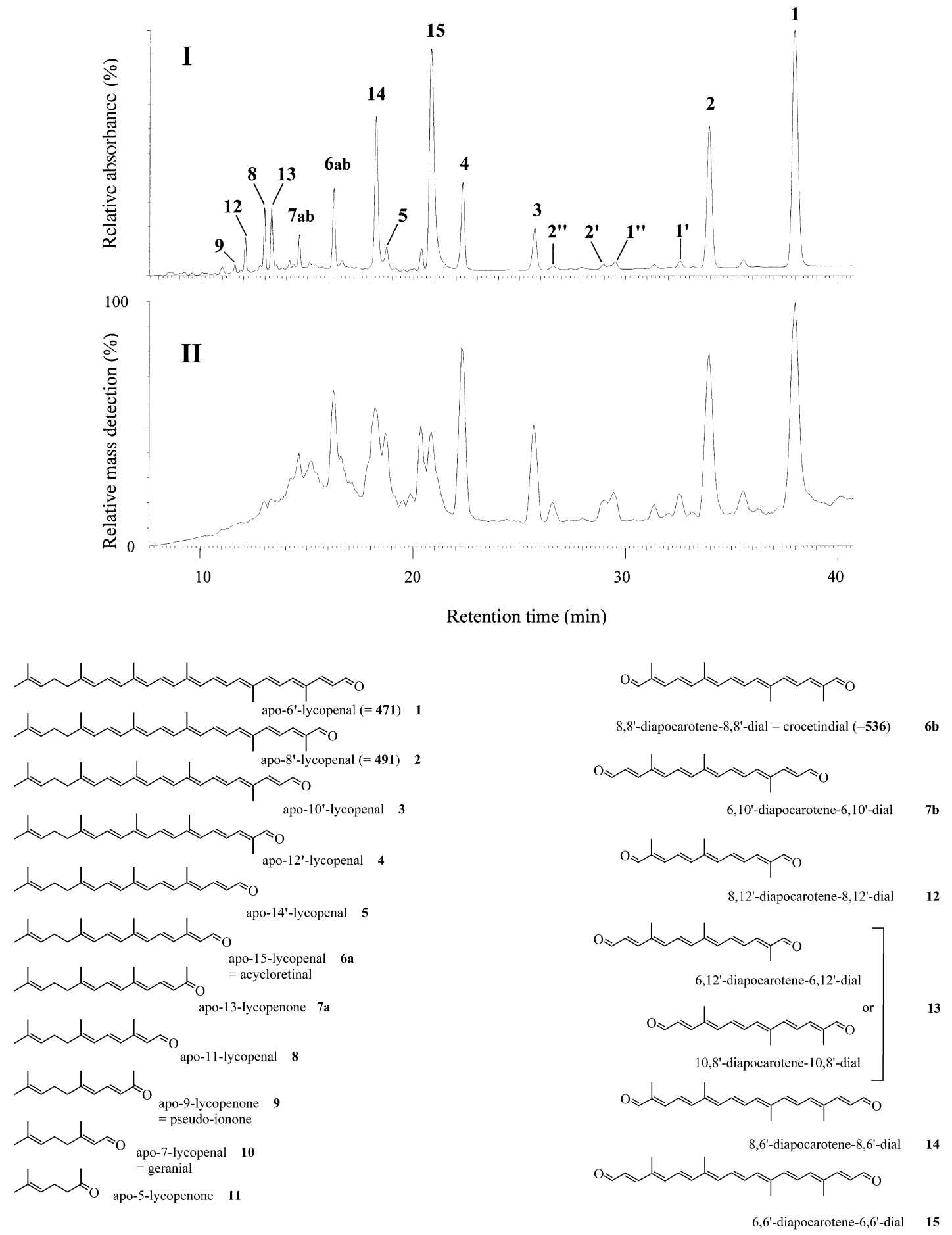

Fig. 3 UV/vis (I) and ESP+ mass chromatograms (II) of the lycopene oxidation products derived from oxidation with potassium permanganate. Chemical structures of apo-lycopenals/ones and diapo-carotenedials tentatively identified and shown in chromatogram (I). 1' and 1" are (Z)-isomers of compound 1, while $\mathbf{2}^{\prime}$ and $\mathbf{2}^{\prime \prime}$ are (Z)-isomers of compound 2. Compound numbers inside brackets correspond to those used in ref. [1]. Reprinted with permission from [68]. Copyright $\odot 2003$ American Chemical Society. 
mass spectrometry detector (positive electrospray mode; HPLC-DAD-MS) (Fig 3). Two types of products were tentatively identified by their UV/vis and mass spectra: (1) apo-lycopenals and apo-lycopenones derived from a single oxidative cleavage, and (2) diapocarotene-dials derived from a double oxidative cleavage of lycopene (Fig. 3), which thus lost the two $\psi$-end groups of lycopene. No apo-lycopenoic acids were found in the reaction mixture, indicating that in our experimental conditions there was no further oxidation of apo-lycopenals by potassium permanganate. The structures of one member of each family, i.e., apo-11-lycopenal (8) and 8,6'-diapocarotene-8,6'-dial (14), were confirmed by ${ }^{1} \mathrm{H}$ NMR analysis after isolation of the compounds. This oxidation method allowed us to produce the complete range of the possible apo-lycopenals formed by oxidative cleavage of conjugated carbon-carbon double bonds of lycopene and also six diapocarotene-dials, including crocetindial $(\mathbf{6 b})$. According to the HPLC chromatogram (Fig. 3), few if any (Z)-isomers were formed, and the peaks are all rather well separated, which opens up the possibility of preparing these compounds by preparative HPLC for further use.

In the second oxidation method, a metalloporphyrin was used in order to catalyze the carotenoid oxidation by molecular oxygen. This kind of system is used to mimic the active heminic enzyme-type center, such as CYP 450. The carotenoid oxygenases identified to date are not heminic enzymes since the recent X-ray structure analysis of a carotenoid oxygenase showed the presence of 4 histidine residues chelating the iron center [60]. However, it was recently shown that carotenoid hydroxylation is catalyzed by CYP 450 in bacteria [69] and in plants [70,71]. A well-developed and elegant porphyrin model of a catalytic system has been used to mimic the central cleavage of carotenoids [72]. The reaction was about $40 \%$ regioselective for the oxidative cleavage of $\beta$-carotene on its central $\left(15,15^{\prime}\right)$ carbon-carbon double bond. Given that our focus was on the experimental modeling of the eccentric cleavage of carotenoids, we used more simple ruthenium porphyrins as models of iron porphyrins for the oxidation studies on lycopene [68] and $\beta$-carotene [73]. Ruthenium tetraphenylporphyrin catalyzed lycopene oxidation by molecular oxygen, producing $(Z)$-isomers, epoxides, and apo-lycopenals/ones from the longest apo-6'-lycopenal (1) to the shortest apo-9-lycopenone (9) (Fig. 3). All these products had already begun to appear after just $1 \mathrm{~h}$ in the reaction medium, but presented different evolution patterns over the $96 \mathrm{~h}$ of the reaction (Fig. 4). (Z)-isomers of lycopene were detected after $1 \mathrm{~h}$, and had almost disappeared after $24 \mathrm{~h}$ (results not shown). Lycopene epoxide concentrations peaked after $1 \mathrm{~h}$ of reaction and then progressively decreased until 96 h (Fig. 4 I). Concerning apo-lycopenals/ones, the evolution of their concentrations in the reaction medium was structure-dependent. The amount of apo6'-lycopenal (1), which is the longest chain apo-lycopenal, increased over the first $5 \mathrm{~h}$ and then decreased continuously until complete disappearance at $96 \mathrm{~h}$ (Fig. 4 I). Concentrations of apo-8'-lycopenal (2), apo-10'-lycopenal (3), apo-12'-lycopenal (4), apo-14'-lycopenal (5), and apo-15-lycopenal (6a) increased more or less regularly until $48 \mathrm{~h}$ and then decreased until $96 \mathrm{~h}$, with the longest apo-lycopenals ( $\mathbf{2}$ and $\mathbf{3}$ ) disappearing completely (Figs. 4 II and III). Finally, concentrations of the shortest apolycopenals, i.e., apo-13-lycopenone (7a), apo-11-lycopenal (8), and apo-9-lycopenone (9), increased continuously from the beginning of the reaction until it was stopped at $96 \mathrm{~h}$ (Fig. 4 IV). These results suggest a possible mechanism for the oxidation of lycopene by molecular oxygen catalyzed by a metalloporphyrin (Fig. 5). Lycopene (Z)-isomers would be the first products formed, and would be quickly oxidized into lycopene "in-chain" epoxides, which in turn would undergo oxidative cleavage to form apo-lycopenals/ones. The longer-chain apo-lycopenals (apo-15- to apo-6'-lycopenal, 6a to 1) could themselves be oxidized by the metalloporphyrin $/ \mathrm{O}_{2}$ system and thus be cleaved into shorter apo-lycopenals/ones (apo-9- to apo-13-lycopenal/ones, 9 to 7a). A similar system, but with a more "hindered" porphyrin (teramesitylporphyrin $=$ tetraphenylporphyrin bearing 3 methyl substituents in ortho and para positions on each phenyl group), was tested for $\beta$-carotene oxidation by molecular oxygen. This system was chosen to slow the oxidation process and thus make it possible to identify possible intermediates by HPLC-DAD-MS analysis. The system yielded the same product families as with lycopene, i.e., (Z)-isomers, epoxides, and $\beta$-apo-carotenals, together with new products potentially corresponding to 

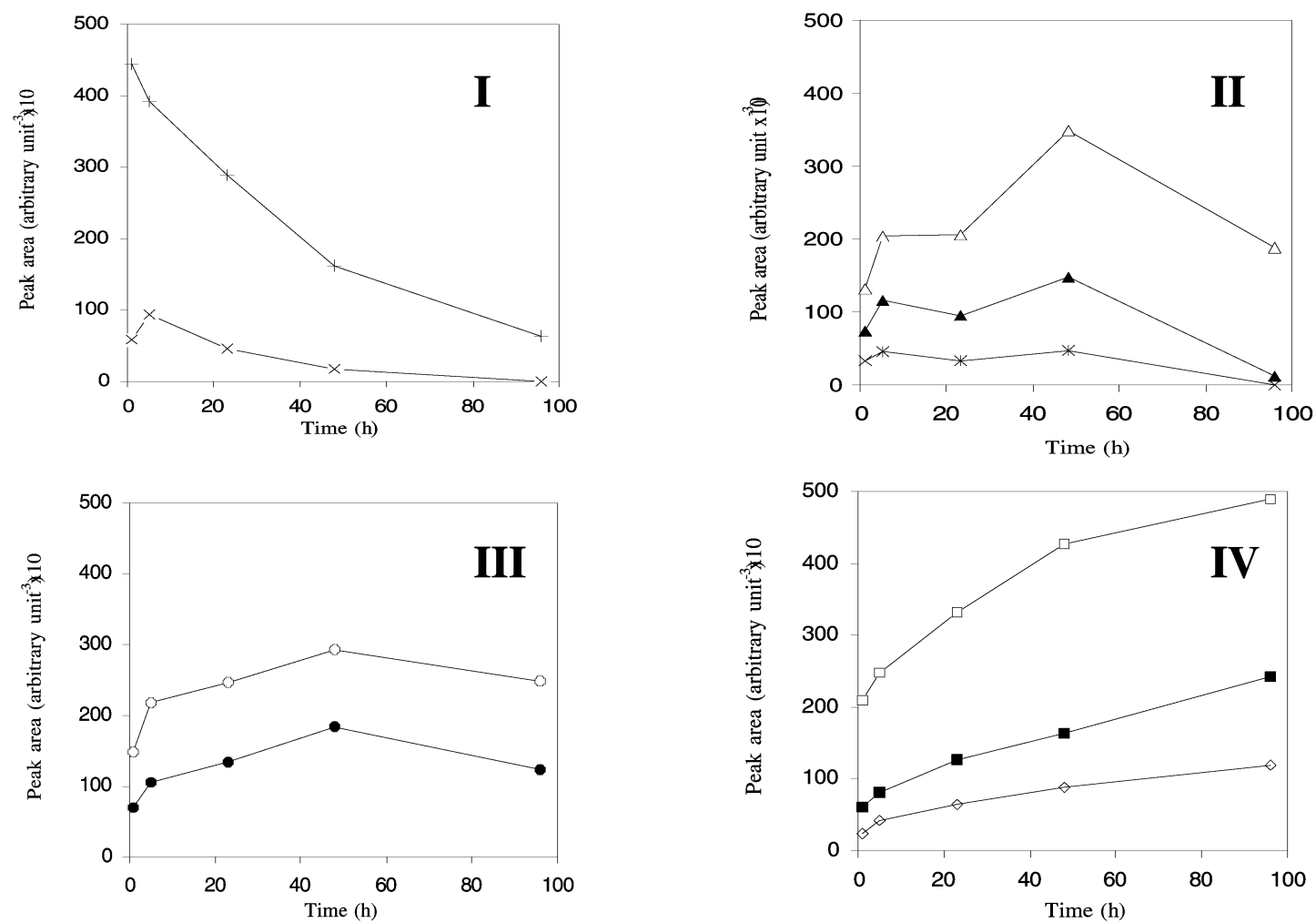

Fig. 4 Evolution patterns of lycopene oxidation compounds derived from ruthenium tetraphenylporphyrincatalyzed oxidation over 96 h. I: lycopene epoxides: + and apo-6'-lycopenal: x; II: apo-12'-lycopenal: $\triangle$, apo10'-lycopenal: $\mathbf{\Delta}$ and apo-8'-lycopenal: *; III: apo-15-lycopenal: $\bullet$ and apo-14'-lycopenal: $\bigcirc$; and IV: apo13-lycopenone: $\square$, apo-11-lycopenone: $\boldsymbol{\square}$ and apo-9-lycopenal: $\diamond$. Reprinted with permission from [68]. Copyright (C) 2003 American Chemical Society.

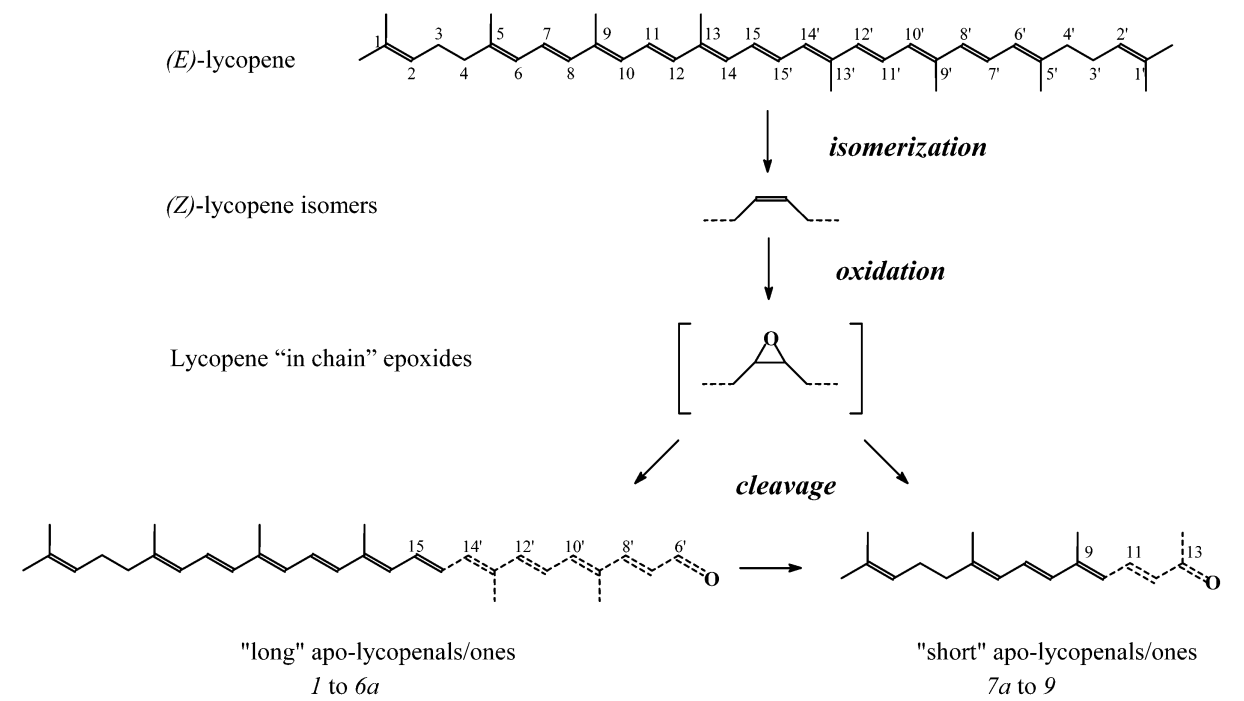

Fig. 5 Possible mechanism for the ruthenium tetraphenylporphyrin-catalyzed oxidation of lycopene by molecular oxygen. Molecule parts in dotted lines indicate that the number of conjugated carbon-carbon double bonds can vary. Reprinted with permission from [68]. Copyright (c) 2003 American Chemical Society. 
diapocarotene-dials and 5,6- and/or 5,8-epoxide of $\beta$-apo-carotenals (Fig. 6). The oxidation mechanism thus appears more complex in this set-up, and may contain other routes (Fig. 6). 5,6-Epoxides of $\beta$-apocarotenals could be formed from either direct epoxidation of $\beta$-carotene followed by subsequent cleavage, or from epoxidation of $\beta$-apo-carotenals formed by a similar mechanism as described for lycopene. 5,6 -Epoxy- $\beta$-apo-carotenals could then rearrange into 5,8-epoxy- $\beta$-apo-carotenals. Diapocarotene-dials could either derive from $\beta$-apo-carotenals or their 5,6-(5,8)-epoxide.

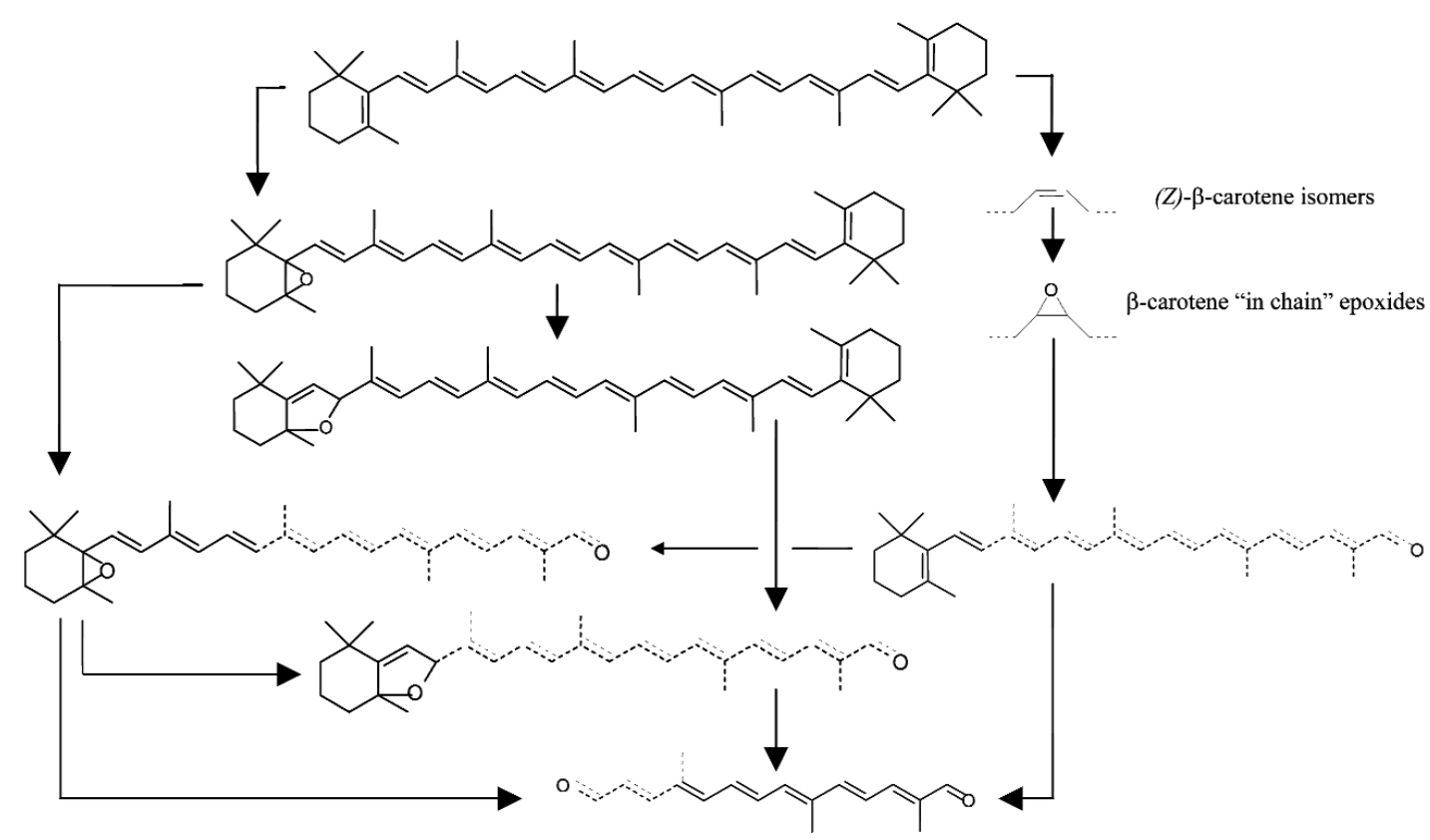

Fig. 6 Possible mechanism for the ruthenium mesitylporphyrin-catalyzed oxidation of $\beta$-carotene by molecular oxygen. Molecule parts in dotted lines indicate that the number of conjugated carbon-carbon double bonds can vary.

In conclusion, different metalloporphyrins were able to catalyze the oxidation of lycopene and $\beta$-carotene by molecular oxygen, producing different types of products. We tracked the appearance of the different reaction products and detected intermediates. The putative identification of intermediates led us to propose possible mechanisms of formation of the final products, i.e., apo-lycopenals and apolycopenones.

Carotenoid oxidation products can thus be formed by different abiotic oxidation systems. These findings could be useful for the identification of possibly bioactive carotenoid oxidation compounds in vivo and thus further our understanding of their mechanisms of formation.

\section{ACKNOWLEDGMENTS}

The author wishes to thank Marie-Jo Amiot from INRA-INSERM in Marseille, France, for the scientific discussions, J. C. Marchon and R. Ramasseul of the French Atomic Energy Commission (CEA) in Grenoble, France, for their kind support in the experiments with the ruthenium metalloporphyrins, and also Antje Schmid and Volker Boehm from the Institute of Nutrition, Friedrich Schiller University in Jena, Germany for their participation to the oxidation by potassium permanganate. Special acknowledgments to Hansgeorg Ernst and Christoph Werner from BASF in Ludwigshafen, Germany, for kindly 
giving me pure samples of apo-8'-, apo-12'-lycopenals and crocetindial, samples which helped us in the confirmation of the structural elucidation of these lycopene oxidation derivatives.

\section{REFERENCES}

1. G. Britton, S. Liaaen-Jensen, H. Pfander (Eds.). Carotenoids: Handbook, Birkhäuser, Basel (2004).

2. IUPAC Commission on the Nomenclature of Organic Chemistry (CNOC) and IUPAC-IUB Commission on Biochemical Nomenclature (CBN). Pure Appl. Chem. 41, 407 (1975).

3. IUPAC Commission on the Nomenclature of Organic Chemistry and IUPAC-IUB Commission on Biochemical Nomenclature. In Carotenoids, O. Isler (Ed.) pp. 851-864, Birkhäuser, Basel (1971).

4. P. Karrer, E. Jucker. Carotenoids, pp. 43-52, Elsevier, Amsterdam (1950).

5. R. Kuhn, A. Winterstein, L. Karlovitz. Helv. Chim. Acta 12, 64 (1929).

6. P. Karrer, H. Helfenstein, H. Wehrli, A. Wettstein. Helv. Chim. Acta 13, 1084 (1930).

7. R. Kuhn, C. Grundmann. Ber. 65, 1880 (1935).

8. P. Uebelhart, C. H. Eugster. Helv. Chim. Acta 71, 1983 (1988).

9. T. A. Kennedy, D. C. Liebler. Chem. Res. Toxicol. 4, 290 (1991).

10. P. Winterhalter, R. Rouseff. In Carotenoid-derived Aroma Compounds, ACS Symposium Series 802, p. 1, American Chemical Society, Washington, DC (2001).

11. E. Lewinsohn, Y. Sitrit, E. Bar, Y. Azulay, A. Meir, D. Zamir, Y. Tadmor. J. Agric. Food Chem. 53, 3142 (2005).

12. A. Lutz, P. Winterhalter. Tetrahedron Lett. 33, 5169 (1992).

13. B. Camara, F. Bouvier. Arch. Biochem. Biophys. 430, 16 (2004).

14. F. Bouvier, J. C. Isner, O. Dogbo, B. Camara. Trends Plant Sci. 10, 187 (2005).

15. F. Khachik, G. Beecher, J. C. Smith. J. Cell. Biochem. 22, 236 (1995).

16. T. J. King, F. Khachik, H. Bortkewicz, S. Fukushima, S. Morioka, J. S. Bertram. Pure Appl. Chem. 69, 2135 (1997).

17. X. D. Wang. In Carotenoids in Health and Disease, N. I. Krinsky, S. T. Mayne, H. Sies (Eds.), pp. 313-335, Marcel Dekker, New York (2004).

18. M. Hanusch, W. Stahl, W. A. Schulz, H. Sies. Arch. Biochem. Biophys. 317, 423 (1995).

19. O. Aust, N. Ale-Agha, L. Zhang, H. Wollersen, H. Sies, W. Stahl. Food Chem. Toxicol. 41, 1399 (2003).

20. E. Nara, H. Hayashi, M. Kotake, K. Miyashita, A. Nagao. Nutr. Cancer Intern. J. 39, 273 (2001).

21. X. M. Hu, K. M. White, N. E. Jacobsen, D. J. Mangelsdorf, L. M. Canfield. J. Nutr. Biochem. 9, 567 (1998).

22. A. Ben-Dor, A. Nahum, M. Danilenko, Y. Giat, W. Stahl, H.-D. Martin, T. Emmerich, N. Noy, J. Levy, Y. Sharoni. Arch. Biochem. Biophys. 391, 295 (2001).

23. E. C. Tibaduiza, J. C. Fleet, R. M. Russell, N. I. Krinsky. J. Nutr. 132, 1368 (2002).

24. E. Kotake-Nara, S. J. Kim, M. Kobori, K. Miyashita, A. Nagao. Anticancer Res. 22, 689 (2002).

25. O. Sommerburg, C. D. Langhans, S. Fulda, K. Mohr, I. Wiswedel, K. M. Debatin, M. Leichsenring, S. Werner. Free Radical Biol. Med. 33, S332 (2002).

26. H. Zhang, E. Kotake-Nara, H. Ono, A. Nagao. Free Radical Biol. Med. 35, 1653 (2003).

27. P. Prakash, C. Liu, K. D. Hu, N. I. Krinsky, R. M. Russel, X. D. Wang. J. Nutr. 134, 667 (2004).

28. R. Rühl, R. Sczech, N. Landes, P. Pfluger, D. Kluth, F. J. Schweigert. Eur. J. Nutr. 43, 336 (2004).

29. F. Khachik, G. Beecher, M. B. Goli, W. R. Lusby, J. C. J. Smith. Anal. Chem. 64, 2111 (1992).

30. F. Khachik, C. J. Spangler, J. C. Smith, L. Canfield, A. Steck, H. Pfander. Anal. Chem. 69, 1873 (1997).

31. F. Khachik, A. Steck, U. A. Niggli, H. Pfander. J. Agric. Food Chem. 46, 4874 (1998).

32. T. J. King, F. Khachik, H. Bortkewicz, S. Fukushima, S. Morioka, J. S. Bertram. Pure Appl. Chem. 69, 2135 (1997). 
33. M. Pastori, H. Pfander, D. Boscoboinik, A. Azzi. Biochem. Biophys. Res. Com. 250, 582 (1998).

34. The $\alpha$-Tocopherol, $\beta$-Carotene Cancer Prevention Study Group. N. Engl. J. Med. 330, 1029 (1994).

35. G. S. Omenn, G. E. Goodman, M. D. Thornquist, J. Balmes, M. R. Cullen, A. Glass, J. P. Keogh, F. L. Meyskens Jr., B. Valanis, J. H. Williams Jr., S. Barnhart, S. Hammar. N. Engl. J. Med. 334, 1150 (1996).

36. X. D. Wang, C. Liu, R. T. Bronson, D. E. Smith, N. I. Krinsky, M. Russel. J. Natl. Cancer Inst. 91, 60 (1999).

37. S. Gradelet, J. Leclerc, M. H. Siess, P. O. Astorg. Xenobiotica 26, 909 (1996).

38. C. Liu, R. M. Russel, X. D. Wang. J. Nutr. 133, 173 (2003).

39. M. G. Salgo, R. Cueto, G. W. Winston, W. A. Pryor. Free Radical Biol. Med. 26, 162 (1999).

40. W. Augustin, W. Siems, O. Sommerburg, C. D. Langhans, L. Schild, I. Wiswedel. Free Radical Biol. Med. 33, S326 (2002).

41. O. Sommerburg, A. Alija, N. Bresgen, P. M. Eckl, W. Siems. Free Radical Biol. Med. 36, S56 (2004).

42. S.-L. Yeh, M.-L. Hu. Food Chem. Toxicol. 41, 1677 (2003).

43. S. H. Schwartz, B. C. Tan, D. A. Gage, J. A. D. Zeevaart, D. R. McCarty. Science 276, 1872 (1997).

44. B. C. Tan, L. M. Joseph, W. T. Deng, L. J. Liu, Q. B. Li, K. Cline, D. R. McCarty. Plant J. 35, 44 (2003).

45. F. Jüttner, B. Höflacher. Arch. Microbiol. 141, 337 (1985).

46. F. Bouvier, C. Suire, J. Mutterer, B. Camara. Plant Cell 15, 47 (2003).

47. F. Bouvier, O. Dogbo, B. Camara. Science 300, 2089 (2003).

48. S. H. Schwartz, X. Q. Qin, J. A. D. Zeevaart. J. Biol. Chem. 276, 25208 (2001).

49. S. Mathieu, N. Terrier, J. Procureur, F. Bigey, Z. Günata. J. Exp. Bot. 56, 2721 (2005).

50. H. Steenbock. Science 50, 532 (1919).

51. T. Moore. Biochem. J. 24, 692 (1930).

52. J. A. Olson, O. Hayaishi. Proc. Natl. Acad. Sci. USA 54, 1364 (1965).

53. D. S. Goodman, H. S. Huang. Science 149, 879 (1965).

54. J. von Lintig, K. Vogt. J. Biol. Chem. 275, 11915 (2000).

55. A. Wyss, G. Wirtz, W. D. Woggon, R. Brugger, M. Wyss, A. Friedlein, H. Bachmann, W. Hunziker. Biochem. Biophys. Res. Commun. 271, 334 (2000).

56. A. Wyss, G. M. Wirtz, W. D. Woggon, R. Brugger, M. Wyss, A. Friedlein, G. Riss, H. Bachmann, W. Hunziker. Biochem. J. 354, 521 (2001).

57. T. M. Redmond, S. Gentleman, T. Duncan, S. Yu, B. Wiggert, E. Gantt, F. X. Cunningham. J. Biol. Chem. 276, 6560 (2001).

58. J. Paik, A. During, E. H. Harrison, C. L. Mendelsohn, K. Lai, W. S. Blaner. J. Biol. Chem. 276, 32160 (2001).

59. M. G. Leuenberger, C. Engeloch-Jarret, W. D. Woggon. Angew. Chem., Int. Ed. 40, 2614 (2001).

60. D. P. Kloer, S. Ruch, S. Al-Babili, P. Beyer, G. E. Schulz. Science 308, 267 (2005).

61. C. Kiefer, S. Hessel, J. M. Lampert, K. Vogt, M. O. Lederer, D. E. Breithaupt, J. von Lintig. J. Biol. Chem. 276, 14110 (2001).

62. R. V. Sharma, S. N. Mathur, A. A. Dmitrovskii, R. C. Das, J. Ganguly. Biochim. Biophys. Acta 486, 183 (1976).

63. X. D. Wang, R. P. Marini, X. Hebuterne, J. G. Fox, N. I. Krinsky, R. M. Russell. Gastroenterology 108, 719 (1995).

64. X. Hebuterne, X. D. Wang, D. E. H. Smith, G. W. Tang, R. M. Russell. J. Lipid Res. 37, 482 (1996).

65. J. D. Surmatis, A. Ofner, J. Gibas, R. Thommen. J. Org. Chem. 31, 186 (1966).

66. H. Kjoesen, S. Liaaen-Jensen. Phytochemistry 8, 483 (1969). 
67. M. Zurcher, H. Pfander. Tetrahedron 55, 2307 (1999).

68. C. Caris-Veyrat, A. Schmid, M. Carail, V. Böhm. J. Agric. Food Chem. 51, 7318 (2003).

69. F. Blasco, I. Kauffmann, R. D. Schmid. Appl. Microbiol. Biotechnol. 64, 671 (2004).

70. L. Tian, V. Musetti, J. Kim, M. Magallanes-Lundback, D. DellaPenna. Proc. Natl. Acad. Sci. USA 101, 402 (2004).

71. K. Inoue. Trends Plant Sci. 9, 515 (2004).

72. R. R. French, P. Holzer, M. G. Leuenberger, W. D. Woggon. Angew. Chem., Int. Ed. 39, 1267 (2000).

73. C. Caris-Veyrat, M. J. Amiot, R. Ramasseul, J. C. Marchon. New J. Chem. 25, 203 (2001). 